\title{
Organização Institucional da Gestão Hídrica no Ordenamento Ambiental Brasileiro: Aspectos Regulatórios
}

\author{
Institutional Organization of Water Management in the Brazilian \\ Environmental Planning: Regulatory Aspects
}

1 Benevenuto Silva Santos benevenutofss@uol.com.br
1 Igor de Abreu

1 Docente do Centro Universitário de Volta Redonda, UniFOA.

\section{RESUMO}

A gestão integrada dos mananciais hídricos é tema recente de nossa legislação. A despeito de ser indispensável à vida humana, a questão hídrica no Brasil sempre foi objeto de uma visão primordialmente energética, sendo subsidiariamente tratados os demais temas relacionados ao uso deste insumo. Não é assim o correto. Deve-se ter em mente que as fontes hídricas possuem múltiplos usos, desde o consumo humano, passando pela matriz hidrelétrica, e chegando ao sistema de agroprodução. Para normatizar o uso da água, existe um sistema regulatório, cuja importância se reflete no desempenho de atividade econômica. Trata-se da proteção de um bem difuso, importante para a prestação de várias modalidades de serviços públicos (água potável, transporte, irrigação), cuja gestão cabe ao Poder Público, com a devida participação da sociedade.

\section{PALAVRAS-CHAVE}

água; gestão; governo; regulação; sociedade.

\begin{abstract}
The integrated management of water sources is a recent theme of our legislation. Despite being essential to human life, the water issue in Brazil has always been the object of a primarily energy vision, and treated secondarily other topics related to the use of this input. That is not correct. It should be borne in mind that water supplies have multiple uses, such as human consumption, hydroelectric matrix and agricultural production system. To regulate the use of water, there is a regulatory system whose importance is reflected in the performance of the economic activity. It is the protection of a diffuse commodity, important for the provision of various public services modalities (drinking water, transport, irrigation), which is managed by the Government, with society's due participation.
\end{abstract}

\section{KEYWORDS}

water; management; government; regulation; society.

\section{Como você deve citar?}

SANTOS, Benevenuto Silva; ABREU, Igor. Organização Institucional da Gestão Hídrica no Ordenamento Ambiental Brasileiro: Aspectos Regulatórios. Cadernos UniFOA, Volta Redonda, n. 29, p. 61-75, dez. 2015. 


\section{INTRODUÇÃO}

O arcabouço constitucional sobre o meio ambiente, em nosso ordenamento, é pautado em algumas condicionantes que convergem para a garantia de um desenvolvimento sustentável, acautelando-se os empreendimentos e atividades potencialmente danosas, tanto particulares quanto estatais, e reconhecendo o ecossistema e os bens naturais como matéria de relevante interesse, sujeitando-os a instrumentos regulatórios que permitam a sua preservação às demais gerações. Para dar ênfase a estes pressupostos, a Constituição Federal tratou a defesa do meio ambiente como uma questão de interesse difuso, conforme previsto no seu art. 225, dispondo, também, esta proteção como um dos elementos necessários ao desempenho de atividade econômica, como nos coloca o art. 170.

A proteção do meio ambiente constitui, por conseguinte, norma constitucional programática, ${ }^{2}$ devendo o Poder Público elaborar um arcabouço normativo e administrativo que dê cumprimento à Constituição da República. Dentre o conjunto normativo colocado para a proteção do meio ambiente, pode-se delimitar a questão hídrica sob as seguintes bases:

1. a titularidade pública dos bens ambientais, nitidamente rios e fontes hídricas, em que o Estado promoverá a sua proteção em benefício da sociedade e das futuras gerações, podendo, para tanto, limitar o seu uso; e

2. a normatização de sistema de gestão de recursos hídricos, visando critérios de outorga, considerando a possibilidade de sua escassez, reservando à água um valor econômico na sua utilização.

0 acesso à água assume, assim, preponderante aspecto federativo regionalizante em algumas localidades, principalmente sob o enfoque urbano, pois o ambiente protegido é questão de qualidade de vida das cidades brasileiras, sendo, também, uma das formas de proteção do espaço urbano.

\section{DOMÍNIO PÚBLICO E QUALIFICAÇÃO DO BEM HÍDRICO}

Nos termos do art. 225 da Constituição Federal, o meio ambiente é um complexo (de ecossistemas) de direito difuso, sendo um bem de uso comum do povo e essencial à sadia qualidade de vida, impondo-se ao Poder Público e à coletividade o dever de defendê-lo e preservá-lo para as seguintes e futuras gerações. Dessa forma, atribui-se ao meio ambiente a conceituação de bem difuso, cabendo ao Estado conciliar o uso racional dos bens naturais.

Excelente colocação nos faz Paulo Affonso Leme Machado ao mostrar que a dominialidade pública da água não transforma o Poder Público federal e estadual em proprietário da água, mas gestor desse bem. ${ }^{3}$ A consequência desta visão exclui a água como parte do patrimônio privado do Estado, não lhe sendo conceituado como bem dominical.

O uso racional significa a possibilidade de impor restrições à utilização dos recursos hídricos. $\mathrm{A}$ fruição de alguns serviços públicos depende diretamente dos recursos hídricos, como, por exemplo, o

\footnotetext{
2 As normas programáticas procuram dizer ao Estado para onde e como se vai, característica relevante aos princípios gerais de toda a ordem jurídica (SILVA, 2000, p. 141). A Constituição de 88 é mais incisiva no conceber a ordem econômica sujeita aos ditames da justiça social para o fım de assegurar a todos existência digna.

3 MACHADO, P. A. L., 2006. p. 432.
} 
fornecimento de energia, pois a matriz energética brasileira é estruturada na utilização dessas fontes. ${ }^{4}$ Outros serviços de interesse coletivo também demandam a utilização de bens ambientais, tais como navegação e fornecimento de água potável. Para esta finalidade, os bens ambientais estão dispostos, em sua maioria, como bens da União ou dos Estados federados, na forma estabelecida nos artigos 20 e 26 da Carta Federativa Brasileira.

0 art. 20 da Constituição Federal reservou para a União o domínio sobre os lagos, rios e quaisquer correntes de água em terrenos de seu domínio, ou que banhem mais de um Estado, sirvam de limites com outros países, ou se estendam a território estrangeiro ou dele provenham, bem como os terrenos marginais e as praias fluviais (inciso III), bem como os potenciais de energia hidráulica (inciso VIII).

Aos Estados, por exclusão, na forma do art. 26, inciso l, é reservado o domínio sobre as águas superficiais ou subterrâneas, fluentes, emergentes e em depósito, ressalvadas, neste caso, na forma da lei, as decorrentes de obras da União.

A utilização econômica de bens ambientais, mesmo em se tratando de serviços de interesse público, deve ser pautada na sua sustentabilidade, sendo expressa na Constituição Federal a obrigação de o Poder Público proteger a fauna e a flora, vedadas as práticas que coloquem em risco sua função ecológica, provoquem extinção de espécies ou submetam os animais a crueldade. ${ }^{5}$

\section{DISTRIBUIÇÃO CONSTITUCIONAL DE COMPETÊNCIAS EM MATÉRIA AMBIENTAL}

A Constituição Federal traçou alguns dispositivos essenciais à proteção e à gestão do meio ambiente, que, consequentemente, se aplica a todos os entes federativos, nos seguintes termos:

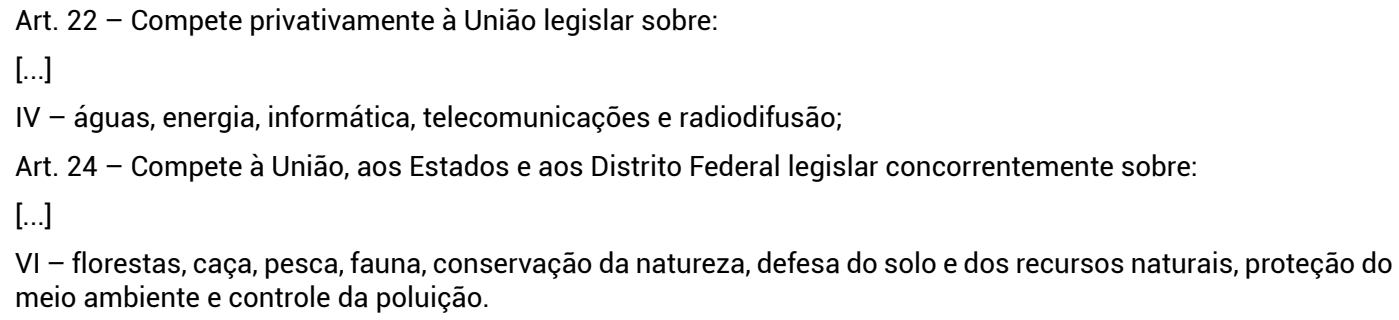

Dificilmente alguma questão referente ao meio ambiente estará fora do alcance dos pontos e tópicos traçados nos dispositivos acima. A tratativa referencial sobre as medidas administrativas e sociais de repercussão ambiental concentra-se, contudo, em capítulo constitucional próprio.

0 art. 225, da Constituição Federal, já citado, estatui o dever de o Estado atuar na preservação ecológica, na biodiversidade e no patrimônio genético, a criação de unidades de conservação ambiental, o estudo de impacto ambiental, promoção da educação ambiental e proteção da fauna e da flora em geral.

Em outros dispositivos constitucionais são abordadas matérias que se aplicam a questões que incidem sobre o meio ambiente, localizando-se, nestes casos, dentre as competências da União, as diretrizes gerais para o desenvolvimento urbano, inclusive habitação, saneamento e transportes urbanos, consubstanciado no art. 21, XX; o estabelecimento de normas concorrentes em direito urbanístico (art.

4 É competência da União, conforme art. 21,XII, explorar os serviços e instalações de energia elétrica o o aproveitamento dos cursos de água, em articulação com os Estados onde se situam os potenciais hidroenergéticos.

5 Art. 225, IV e VII, Constituição Federal. 
24, I); e a fixação de diretrizes gerais para a política urbana municipal (art. 182). Todos estes dispositivos delegam à União o papel de entidade reguladora geral das matérias relativas ao ambiente urbano. Além desses dispositivos, a Constituição Federal também remete à União a competência para instituir um sistema nacional de gerenciamento de recursos hídricos, definindo os critérios de outorga de direitos de seu uso, nos termos art. 21, XIX.

A questão hídrica também faz parte de um importante contexto de políticas públicas de redução das desigualdades sociais e regionais, contido no art. 43, da Constituição Federal. 0 papel articulador da União nas regiões administrativas instituídas em lei complementar para a execução de programas inter-regionais, ${ }^{6}$ compreende o aproveitamento de rios e de águas represadas, em localidades sujeitas a secas periódicas. ${ }^{7}$

Os dispositivos constitucionais referentes ao domínio federal e estadual sobre as águas e a competência concorrente da União e dos Estados membros não eliminou a possibilidade de atuação dos Municípios, cabendo-Ihe o exercício das atribuições relacionadas ao interesse local, como dispõe o art. 30, I, Constituição Federal. ${ }^{8}$

Evidente que, para o Município, tal competência em matéria ambiental e de proteção dos mananciais hídricos dar-se-ia muito mais em razão de controle sobre o solo urbano e na proteção ao meio ambiente restrita aos seus aspectos territoriais. Para tanto, a Constituição Federal, em seu art. 23, permite aos municípios a atuação em matérias ambientais, cuja competência é comum à União, aos Estados e ao Distrito federal.

Com esse viés, a Lei Complementar 140, de 08 de dezembro de 2012, fixou normas para a cooperação entre as pessoas políticas nas ações administrativas decorrentes do exercício da competência comum relativas à proteção das paisagens naturais notáveis, à proteção do meio ambiente, ao combate à poluição em qualquer de suas formas, além da preservação das florestas, da fauna e da flora. Esta Lei federal veio a descrever as ações administrativas das esferas governamentais, que, de certa forma, interagem e incidem sobre temas conexos em matéria ambiental.

\section{A UTILIZAÇÃO DOS RECURSOS HÍDRICOS - ASPECTOS ECONÔMICOS E SOCIAIS}

O uso dos recursos hídricos pode ser classificado em consuntivo ou não-consultivo. Os usos consuntivos são perdas de água resultante de sua utilização, ${ }^{9}$ referem-se ao que diminui espacial e temporalmente nas disponibilidades quantitativas e/ou qualitativas de um corpo hídrico, ou seja, quando há perdas entre o que é retirado e o que retorna ao curso natural. Os principais usos consuntivos dos recursos hídricos são: abastecimento humano, industrial, dessedentação animal e irrigação. ${ }^{10}$

\footnotetext{
6 Em se tratando de políticas de desenvolvimento regional, principalmente no semi-árido nordestino, a interesse da União é empreendido como um dos estímulos positivos de incentivo à economia. A manutenção de organismos de desenvolvimento regionais, tais como Departamento Nacional de Obras Contra as Secas, Superintendência de Desenvolvimento do Nordeste e Companhia de Desenvolvimento dos Vales de são Francisco e Parnaíba, demonstram o alto grau de participação política federal em harmonizar obras e outros instrumentos de estímulo à economia naquela região.

7 Floriano Azevedo, em parecer formulado ao Ministério das Cidades referente à legislação federal sobre normas gerais em matéria de saneamento básico, PL 5296/06, descreve que entidade da União já atuou como concessionário dos serviços públicos de água e esgoto, por intermédio de sociedade de economia mista vinculada à SUDENE, denominada CAENE, Companhia Nordestina de Água e Esgoto, cuja atuação deu-se no norte de Minas Gerais, na região de Montes Claros.

8 Cf. MACHADO, P.A.L. 2002. p.25

9 In LEAL, M. S. p. 7

10 São usos consuntivos na bacia do rio Paraíba do Sul, exemplificando, as seguintes situações: abastecimento de cidades, vilas e povoados; abastecimento de populações humanas do meio rural; consumo industrial; consumo de agroindústrias; irrigação; aquacultura; dessedentação animal. Cf. AQUINO, L.C.S. at al. p. 1-13.
} 
O consumo de água varia na área urbana e rural, e de acordo com o poder aquisitivo, havendo o aumento na demanda devido à melhoria do nível econômico e social (pode-se levar em conta que a água nem sempre chega às populações de periferia, sendo o seu acesso uma melhoria da qualidade de vida). O uso não consuntivo está associado ao que não implica em redução da disponibilidade quantitativa e/ou qualitativa de água nos corpos hídricos, ou seja, quando não há perdas entre o que é retirado e o que retorna ao curso natural, mas podendo haver modificação no seu padrão espacial e temporal.

Deve-se conciliar, portanto, estes interesses dentro de uma visão realista da importância deste recurso para o desenvolvimento e crescimento da sociedade. 0 uso de um rio, ou fonte hídrica, com potenciais hidráulicos, tende a favorecer o sistema energético interligado que, consequentemente, repercutirá na capacidade de crescimento das atividades industriais. Caberá ao Poder Público e à sociedade, contudo, provocar o debate sobre as formas utilização e a preservação dos rios, conjugando interesses sociais e econômicos, como já vem ocorrendo no Brasil, por intermédio dos planos de recursos hídricos junto às bacias hidrográficas, assunto que será tratado nos próximos seguimentos.

\section{A INTEGRAÇÃO ENTRE A GESTÃO AMBIENTAL E A GESTÃO DE RECURSOS HÍDRICOS}

Pode-se entender a proteção da água dentro de um conjunto de normas jurídicas que disciplinam a atuação da Administração Pública e dos particulares, visando à melhoria da qualidade da vida e do meio ambiente, garantindo o seu uso sustentável. A Constituição Federal reconheceu esta questão, ao dispor que o Poder Público estabelecerá meios de outorgar a exploração de recursos hídricos, ${ }^{11}$ estudos de impacto ambiental no licenciamento de atividade potencialmente poluidora, ${ }^{12}$ obrigatoriedade de recuperar o meio ambiente degradado em caso de exploração de recursos minerais, ${ }^{13}$ e na utilização de florestas e zona costeira ${ }^{14}$ e de unidades de conservação ambiental.

O sistema de gestão de recursos hídricos coexiste ou está inserido no sistema de gestão ambiental, o que os torna complementares um ao outro. A implantação de um sistema de gestão de recursos hídricos atende à necessidade compatibilizar os conflitos gerados pelo uso da água, antevendo a possibilidade de escassez em uma eventual incapacidade de atender às demandas. Neste raciocínio, tomemos por exemplos o lançamento de esgoto in natura, a deposição de lixo em áreas com lençóis freáticos que penetram nos rios, as captações irregulares para abastecimento, a impermeabilização do solo, além do lançamento de produtos e resíduos poluentes pelas indústrias, ações que tornam o meio ambiente urbano propenso a danos com forte impacto ambiental.

Embora haja instrumentos regulatórios similares entre a gestão de recursos hídricos e a gestão ambiental, há uma diferença marcante: a executividade. A gestão ambiental tende a ser regulatória e fiscalizatória, enquanto a gestão de recursos hídricos deve possuir um caráter executivo, sob a forma de programas de intervenções físicas que resultem em recuperação, preservação e/ou ampliação da oferta hídrica, projetos e obras de recuperação de bacias hidrográficas e de despoluição de rios, lagoas e baías. ${ }^{15}$

É importante abrir um parêntese: o domínio da fonte hídrica não significa exclusividade na prestação do serviço público que dela dependa. Tomemos como exemplo o domínio sobre as jazidas, que não

\footnotetext{
11 Art. 21, XIX, Constituição Federal.

12 Art. 225, IV, Constituição Federal.

13 Art. 225, § $2^{\circ}$, Constituição Federal.

14 Art. 225, III.

15 No plano federal, o Ministério da Integração Nacional tem atribuição de planejar, coordenar e executar programas de manutenção da infra-estrutura hídrica, conforme dispõe a Lei 10.683, de 28 de maio de 2003, em seu art. 27, XIII; este detalhe o torna gestor da política de obras de transposição do rio São Francisco.
} 
torna a União proprietária dos produtos resultantes da indústria de mineração, assim como o domínio sobre rodovias não torna a União proprietária dos veículos que nelas trafegam. Assim, a dominialidade dos rios e demais fontes hídricas não torna a União prestadora dos serviços públicos de saneamento.

A possibilidade de escassez da água impõe a cooperação entre as esferas governamentais, prevalecendo o interesse de escala territorial mais abrangente. A coordenação entre sistemas regulatórios busca resultados uniformes, sem, contudo, enfraquecer a atuação dos poderes públicos locais, tampouco alienar suas respectivas competências, servindo, ao contrário, para o fortalecimento das capacidades institucionais e administrativas dos níveis envolvidos. ${ }^{16}$

Em se tratando de meio ambiente, convém advertir, a coordenação entre as esferas governamentais vem expressa no art. 23, VI, da Constituição Federal, que versa sobre as competências comuns, que, segundo Paulo de Bessa Antunes, é uma verdadeira armadilha, visto que a atribuição de todos acaba se tornando atribuição de ninguém. ${ }^{17}$

\section{O SISTEMA NACIONAL DE RECURSOS HÍDRICOS}

A promulgação da Constituição Federal de 1988 criou as condições para a inauguração de uma nova etapa na gestão de recursos hídricos, a partir da competência da União para instituir um sistema nacional de gerenciamento de recursos hídricos e definir critérios de outorga de direitos do uso da água (art. 21, inciso XIX).

A Lei de Recursos Hídricos (Lei $n^{\circ}$ 9.433/97) veio ao encontro dos principais aspectos de um modelo sistêmico de integração participativa, mas não prescindiu da outorga do uso dos recursos hídricos, mecanismo que os Governos dispõem para promover o uso adequado da água, visando ao bem estar das futuras gerações. A vantagem desse modelo é compatibilizar a utilização do bem hídrico com o equilíbrio ambiental, no âmbito de um núcleo de planejamento na bacia hidrográfica.

Algumas constituições estaduais, promulgadas em seguida à Constituição Federal, já haviam estabelecido modelos de gestão de seus recursos hídricos, na qualidade de detentores desse bem, como São Paulo, Rio de Janeiro, Ceará, Minas Gerais, Rio Grande do Sul, Santa Catarina, Bahia, Sergipe, Rio Grande do Norte, Paraíba, Pará e Pernambuco, além do Distrito Federal. ${ }^{18}$

Os parâmetros para o funcionamento de um sistema integrado de gestão de recursos hídricos decorrem de lei federal, mas não excluem, entretanto, a autonomia dos Estados na gestão de sua fonte hídrica, que deverá ser exercida no contexto da bacia hidrográfica a qual pertencer. A autonomia conferida aos Estados não deve e não pode comprometer o sistema integrado das bacias, principalmente quando o rio sob o domínio de uma esfera for tributário à outra esfera. Prevalece a supremacia do interesse nacional sobre o local.

Os investimentos em bacias hidrográficas são geralmente elevados e compreendem reservatórios, sistemas de tratamento e abastecimento de água e de coleta e tratamento de esgoto, sistemas de irrigação, criação e fiscalização de reservas etc. Portanto, a melhor forma de se financiar os investimentos em bacias hidrográficas é a cobrança pelo uso da água e o rateio dos custos dos investimentos entre os usuários ou beneficiários.

16 Cf. Marta ARRETCHE apud BERCOVICCI, Gilberto. Dilemas do estado federal brasileiro. Porto Alegre: Livraria do Advogado. p. 70.

17 Cf. Direito Ambiental. 9. ed. Rio de Janeiro: Lumen Juris. 2006. p. 77.

18 Para acesso às diversas leis estaduais, vide TOMANIK, C. Direito das águas no Brasil. São Paulo: Revista dos Tribunais, 2006. p.230. 
Em um meio ambiente equilibrado ecologicamente, as águas se colocam como condição indispensável à boa qualidade de vida da população. A água é um direito cujo conteúdo se insere os direitos fundamentais básicos. ${ }^{19}$ Interpretando a contrário sensu, sem uma gestão eficiente dos recursos hídricos, no futuro, o abastecimento de água, e, principalmente, a coleta e o tratamento de esgotos, podem requerer uma política nacional, conjugando ações da União, dos Estados e DF e dos municípios, afastando-se (ou questionando) a visão de um interesse primordialmente local que é vislumbrada atualmente.

A Política Nacional de Recursos Hídricos (PNRH), instituída a partir do comando da Lei de Águas, baseia-se nos fundamentos e princípios descritos a seguir, que em sua maioria também estão previstos nas leis estaduais de águas:

- A água é um bem de domínio público, deixando de existir, conforme dito, dominialidade privada, prevista no Código de Águas até a promulgação da Constituição de 88.

- A água é um recurso natural, limitado e dotado de valor econômico. Este fundamento é um indutor do uso racional e serve de base para a instituição da cobrança pelo uso da água bruta.

- A gestão dos recursos hídricos deve sempre proporcionar o uso múltiplo das águas; este fundamento preconiza o acesso à água em condições de igualdade para todos os setores usuários, rompendo o arranjo tradicional no Brasil em que o setor elétrico teve prioridade de acesso aos recursos hídricos. ${ }^{20}$

- Em situações de escassez, o uso prioritário dos recursos hídricos é o consumo humano e a dessedentação de animais.

- A bacia hidrográfica é a unidade territorial para implementação da Política Nacional de Recursos Hídricos e de atuação do Sistema Nacional de Gerenciamento de Recursos Hídricos.

A bacia hidrográfica, como unidade de planejamento, passa, assim, a ter uma relação direta com as questões econômicas, sociais e ambientais da população que a integra, posto que uma ação praticada em determinado local pode impactar outro local situado a quilômetros de distância nesta mesma bacia. Logo, a adoção da bacia como unidade de planejamento constitui-se na opção mais adequada tecnicamente para a gestão dos recursos hídricos ${ }^{21}$.

A gestão dos recursos hídricos deve ser descentralizada e contar com a participação dos entes federativos e da sociedade civil. ${ }^{22}$ Esta filosofia descentralizante representa a delegação do processo decisório para os níveis hierárquicos inferiores, como prevalece no princípio da subsidiariedade, excluídas as matérias que sejam de interesse superior, garantindo a legitimidade das decisões tomadas.

Para que esta participação ocorra, existem os comitês de bacia hidrográfica, que são colegiados institucionais constituídos pelo Poder Público, usuários e sociedade civil, visando ao debate das questões relacionadas ao uso dos recursos hídricos, a sua recuperação e proteção. No âmbito de sua

\footnotetext{
19 DERANI, C. Direito ambiental econômico. São Paulo: Max Limonad, 1997. p. 219.

20 GARRIDO, R. J. S. Estágio atual dos aspectos institucionais da gestão de recursos hídricos no Brasil. In: Lei n. 9.433 de 8 de janeiro de 1997. 2. ed. Brasília: MMA/SRH, 1999.

21 Para regiões áridas e planícies de inundação esta afirmação deve ser adotada com restrições. Nestas regiões a disponibilidade hídrica normalmente é garantida através da construção de estruturas hidráulicas como açudes e canais e nem sempre o recorte da bacia hidrográfica abrange todos os usuários que se beneficiam destas estruturas. Neste caso seria mais adequado adotar outro recorte como por exemplo o da bacia social que é delimitada por atores com preocupações sociais e econômicas comuns. mediante participação deliberativa dos comitês de bacia, reafirmando o princípio de participação do cidadão na esfera pública.
} 
área de atuação, os comitês se destinam a promover o debate das questões relacionadas aos recursos hídricos e a articulação da atuação de entidades intervenientes, acompanhar a execução do Plano de Recursos Hídricos da bacia e sugerir as providências para o cumprimento de suas metas; os comitês também podem propor ao Conselho Nacional e aos Conselhos Estaduais, conforme o caso, as dimensões das acumulações, derivações, captações e lançamentos de pouca expressão para efeito de isenção de obrigatoriedade de outorga de direitos de uso, estabelecer mecanismos de cobrança pelo uso de recursos hídricos e sugerir valores a serem cobrados, promovendo o rateio de custo de obras de uso múltiplo, de interesse comum ou coletivo.

O Sistema Nacional de Gerenciamento de Recursos Hídricos foi concebido à forma do sistema francês de gestão, influenciando bastante o pensamento dos especialistas na elaboração das leis brasileiras. Em seus aspectos legais, convém mencionar que a França é um país de regime unitário, peculiaridade que possibilita a existência de leis únicas que se aplicam em todo território nacional, além de surgirem menos conflitos de atribuições entre as unidades administrativas do País. $\begin{array}{lll}23 & 24 & 25\end{array}$

\section{ATRIBUIÇÕES E PODERES REGULATÓRIOS DA AGÊNCIA NACIONAL DE ÁGUAS}

A Lei 9.984/2000 dispôs sobre a criação da Agência Nacional de Águas (ANA), sob a forma de autarquia federal em regime especial, cuja finalidade é a implementação da Política Nacional de Recursos Hídricos e coordenação do Sistema Nacional de Gerenciamento de Recursos Hídricos, arrematando o contexto normativo da nova concepção de gestão de recursos hídricos.

As atribuições conferidas à ANA pela Lei $9.984 / 00$, por seu art. $4^{\circ}$, podem ser sistematizadas nos seguintes grupos:

1. Outorga e fiscalização do uso de bem, que consiste em autorizar e condicionar o direito de uso de recursos hídricos em corpos de água de domínio da União, e a fiscalização do uso de recursos hídricos nos corpos de água de domínio da União;

2. Desenvolvimento institucional do sistema de gestão dos recursos hídricos, que compreende estimular e apoiar as iniciativas voltadas para a criação de Comitês de Bacia Hidrográfica,

23 LEAL, M. S. Gestão ambiental de recursos hídricos: princípios e aplicações. Rio de Janeiro: CPRM, 1998. p. 68.

24 No sistema unitário, como o Francês, a descentraliza normativa e administrativa decorre de decisão política da Assembléia Nacional.

25 Márcia Leal descreve que a gestão de recursos hídricos na França teve diversas contribuições em termos de regulamentações de caráter mais setorial e culminou com a Lei n. 62-1245, de 16 de dezembro de 1964 (relativa ao regime e à distribuição das águas e à luta contra a poluição), e, posteriormente, com a Lei 92-3, de 03 de janeiro de 1992, que dispôs sobre a gestão integrada de recursos hídricos. Cf. LEAL, 1998. p. 68-69. Segundo a autora, o sistema institucional francês comporta, além dos órgãos ligados ao Estado, entidades colegiadas que representam os usuários e as comunidades. O território Frances foi sistematizado em seis bacias hidrográficas, criando-se um sistema institucional cujos principais organismos, em cada bacia, são comitê da bacia e agência de águas (não ligados especificamente ao Estado) e prefeito coordenador da bacia, assistido pela missão delegada e pela Direção Regional de Meio Ambiente (ligados ao Estado). Os comitês de bacias são órgãos consultivos colegiados que reúnem representantes dos usuários, da coletividade e do Estado, sendo de suas atribuições essencialmente a aprovação do programa plurianual de intervenção na bacia, o estabelecimento das cobranças pelo uso e a solução de desavenças. As agências de bacias são estabelecimentos públicos, com autonomia financeira, que aplicam a política estabelecida pelo comitê através do programa de intervenção. Uma de suas principais funções é o financiamento (subvenção, empréstimo) às entidades públicas e privadas da bacia para realização de estudos e intervenções, proposição dos valores das cobranças (para decisão do comitê), suporte técnico aos usuários e prestar informações sobre a bacia. As agências são tuteladas pelo Ministério do Meio Ambiente. Os comitês e as agências desempenham função de conhecimento e de planificação, não possuindo funções regulamentares ou de polícia, que são exercidas pelo Estado francês. A França é um país de regime unitário. Essa particularidade possibilita a existência de leis únicas que se aplicam em todo o território nacional, além de surgirem menos conflitos de atribuições entre unidades administrativas do país, como ocorre com freqüência em países federativos. O sistema institucional comporta, além dos órgãos ligados ao Estado, entidades colegiadas que representam os usuários e as comunidades. Em 1964 o território francês foi sistematizado em seis bacias hidrográficas, criando-se um sistema institucional cujos principais organismos em cada bacia são o comitê de bacia e a agência de água e prefeito coordenador da bacia, assistido pela missão delegada e pela Direção regional de Meio Ambiente da bacia. 
prestar apoio aos Estados na criação de órgãos gestores de recursos hídricos e estimular a pesquisa e a capacitação de recursos humanos para a gestão de recursos hídricos;

3. Arrecadação tarifária, cujas tarefas são de elaborar estudos técnicos para subsidiar a definição, pelo Conselho Nacional de Recursos Hídricos, dos valores a serem cobrados pelo uso de recursos hídricos de domínio da União (com base nos mecanismos e quantitativos sugeridos pelos Comitês de Bacia Hidrográfica); de implementar, em articulação com os Comitês de Bacia Hidrográfica, a cobrança pelo uso de recursos hídricos de domínio da União; de arrecadar, distribuir e aplicar receitas auferidas por intermédio da cobrança pelo uso de recursos hídricos de domínio da União;

4. Elaboração de estudos técnicos, relacionados à supervisão, controle e avaliação das ações e atividades decorrentes do cumprimento da legislação federal pertinente aos recursos hídricos; para isso, disciplinam, em caráter normativo, a operacionalização dos instrumentos da Política Nacional de Recursos Hídricos; neste contexto, a elaboração de estudos serve para subsidiar a aplicação de recursos financeiros da União em obras e serviços de regularização de cursos de água, de alocação e distribuição de água, e de controle da poluição hídrica, em consonância com o estabelecido nos planos de recursos hídricos;

5. Controle de reservatórios, que abrange o monitoramento das condições de operação de reservatórios por agentes públicos e privados, visando a garantir o uso múltiplo dos recursos hídricos, conforme estabelecido nos planos de recursos hídricos das respectivas bacias hidrográficas;

6. Coordenação da rede hidrometeorológica, que envolve planejamento e a promoção de ações destinadas a prevenir ou minimizar os efeitos de secas e inundações, no âmbito do Sistema Nacional de Gerenciamento de Recursos Hídricos, em articulação com o órgão central do Sistema Nacional de Defesa Civil, em apoio aos Estados e Municípios; além dessas atribuições, este grupo compreende a organização, implantação e gestão do Sistema Nacional de Informações sobre Recursos Hídricos;

7. Proteção de barragens, que compreende a adoção de medidas para regular e fiscalizar, quando envolverem corpos d'água de domínio da União, a prestação dos serviços públicos de irrigação, devendo para tanto organizar, implantar e gerir o Sistema Nacional de Informações sobre Segurança de Barragens (SNISB).

É pertinente observar que a menção feita aos corpos hídricos da União deve ser mitigada, uma vez que legislação federal referente a recursos hídricos aplica-se aos Estados federados brasileiros, que, como já dito, também possuem domínio sobre parcela das fontes hídricas. Além disso, repita-se, compete à União adotar medidas visando à gestão integrada dos recursos hídricos, através do monitoramento do sistema e no estabelecimento de critérios de outorga, que, neste caso, incidem diretamente sobre o volume e as condições de captação. ${ }^{26}$

Deve-se destacar, também, que os poderes regulatórios da ANA concentram-se na gestão do bem hídrico, editando normas para o uso sustentável do bem, faltando-lhe, contudo, os poderes decorrentes de uma autoridade ambiental, no caso, o poder de polícia para aplicar sanções por poluição aos rios.

26 A transferência de mecanismos regulatórios a autarquias, dentro dos moldes entronizados pelo fenômeno da desestatização, não se prende a regulação exclusiva de serviços públicos, podendo atingir a gestão de matéria de interesse público, tal, como ocorre com o sistema de vigilância sanitária e o sistema de saúde suplementar. Alexandre S. Aragão revela que a busca por deste modelo organizativo destina-se a regular as atividades que em geral possuem uma especial sensibilidade para a coletividade. cf. Agências reguladoras e a evolução do direito administrativo econômico. 2ª ed. São Paulo: Forense, 2003. p.268. 


\section{OS INSTRUMENTOS DE GESTÃO DA LEI DAS ÁGUAS}

Para atingir os objetivos da Política Nacional de Recursos Hídricos, a Lei 9.433/97 estabeleceu, em seu art. $5^{\circ}$, cinco instrumentos de gestão:

1. Planos de recursos hídricos (ou planos de bacia hidrográfica);

2. Enquadramento dos corpos de água em classes, segundo os usos preponderantes da água;

3. Sistema de informações sobre recursos hídricos;

4. Cobrança pelo uso de recursos hídricos; e

5. Outorga dos direitos de uso de recursos hídricos.

Os planos de recursos hídricos, ${ }^{27}$ elaborados por bacias hidrográficas, envolvem os Estados que são banhados pela fonte (art. $8^{\circ}$ ), constituindo-se em planos diretores que visam fundamentar e orientar a implementação da política de gestão dos recursos hídricos, devendo conter um diagnóstico atualizado dos recursos hídricos. ${ }^{28}$ É importante ressaltar que o plano é um pré-requisito para a cobrança pelo uso da água, visto que é preciso primeiro definir onde e como os recursos serão utilizados para, então, efetuar a sua arrecadação.

A outorga, outro instrumento importante na gestão de recursos hídricos, constituiu-se em uma garantia de acesso à água, ${ }^{29}$ por conta de sua potencial ou efetiva escassez. Nos termos da Lei 9.433/97, estão sujeitos à outorga os seguintes usos: captação; lançamento de efluentes; extração de água de aquífero subterrâneo; aproveitamento de potenciais hidrelétricos; outros usos que alterem o regime, a quantidade ou a qualidade da água existente em um corpo hídrico.

Cabe destacar a utilização de outorgas para garantir a viabilidade de implementação de planos dos governos. Dessa forma, um Estado que planeje instalar um pólo industrial, por exemplo, poderá visualizar a garantia da disponibilidade hídrica necessária no futuro. ${ }^{30}$ Independe de outorga o uso de recursos hídricos para a satisfação das necessidades de pequenos núcleos populacionais distribuídos no meio rural e os usos considerados insignificantes, ficando a cargo de cada comitê de bacia essa definição.

A outorga de uso é uma consequência do planejamento de uso de águas, colocada como medida estratégica. Para isso, a Lei $9.433 / 97$, em seu art. 13, indica que a outorga tem como objeto assegurar os usos múltiplos dos recursos hídricos. Há situações previstas na Lei que permitem ao gestor

27 Os planos de recursos hídricos, conforme art. 6, Lei 9.433/97, têm por objetivo orientar a implementação e o gerenciamento dos recursos hídricos, devem elaborados com vistas em longo prazo, com horizonte de planejamento compatível com o período de implantação de seus programas e projetos. cf. GRANZIERA, M.L. M. Direito das águas. 2ª ed. São Paulo: Atlas, 2003. p. 137.

28 Inserido neste Plano, também pode-se mencionar: análise de alternativas de crescimento demográfico, de evolução de atividades produtivas e de modificações dos padrões de ocupação do solo; balanço entre disponibilidades e demandas futuras dos recursos hídricos, com identificação de conflitos potenciais; metas de racionalização de uso e melhoria da qualidade dos recursos hídricos disponíveis; programas e projetos a serem implantados para o atendimento das metas previstas; prioridades para outorga de direitos de uso de recursos hídricos; diretrizes e critérios para a cobrança pelo uso dos recursos hídricos; propostas para a criação de áreas sujeitas a restrição de uso, com vistas à proteção dos recursos hídricos.

29 O art. 35, X, Lei 9.433/97, estabelece competir ao Poder Executivo a regulamentação para os critérios gerais de outorga.

30 O regime de outorga tem por finalidade assegurar o controle do uso de água, previsto, inclusive, na Constituição Federal, art. 21, XIX, tratando-a especificamente como instrumento de gestão. É ato de intervenção estatal na esfera privada e de controle de uso de espaço ou bem público, sendo no caso, uma maneira de controle a utilização de um bem de uso comum do povo. 
a suspensão da outorga em situações de calamidade, reversão de degradação ambiental, atendimento a usos prioritários e necessidade de navegabilidade. ${ }^{31}$

Nas palavras de Jerson Kelman, ex-presidente da ANA e da Agência Nacional de Energia Elétrica (ANEEL), "a outorga tem valor econômico para quem recebe porque oferece garantia (relativa, não absoluta) de acesso ao bem escasso". ${ }^{32}$ Conforme o professor:

\begin{abstract}
[...] sem a existência de outorgas, os usuários se comportariam como comensais mal-educados, sentados em torno de uma mesa ao centro da qual se encontra um bolo: todos tendem a comer rápida e atabalhoadamente porque qualquer adiamento de consumo pode resultar no desaparecimento do recurso em boca alheia. Com a outorga, cada usuário sabe que tem um pedaço do bolo reservado em seu nome e pode adiar o consumo para a ocasião que mais lhe interessar.
\end{abstract}

Merecem destaques, neste mesmo roteiro, dois conceitos que são introduzidos na Lei 9.984/00, que dizem respeito à outorga pelo uso da água: outorga preventiva e reserva de disponibilidade hídrica. Este tipo de outorga é interessante, pois permite aos investidores que planejem instalar futuramente um empreendimento na bacia, garantir, desde já, a respectiva disponibilidade hídrica.

O segundo conceito consiste em uma articulação da ANA com a ANEEL, para autorização do uso de potencial de energia hidráulica em rios de domínio da União. Um empreendedor que deseja instalar um aproveitamento hidrelétrico em uma bacia deverá obter, primeiramente, a reserva de disponibilidade hídrica junto à ANA. Esta reserva será transformada, automaticamente, em outorga pelo uso de recursos hídricos, quando o empreendedor receber da ANEEL a concessão para uso do potencial de energia hidráulica. ${ }^{33}$

O sistema de cobrança pelo uso da água é uma maneira de fazer com que os usuários e beneficiários de bacia contribuam diretamente para o financiamento da gestão dos recursos hídricos. Ele se processa através de contribuições financeiras, que serão utilizadas na bacia hidrográfica para financiar ações que favoreçam seu desenvolvimento econômico, respeitando a utilização harmoniosa dos recursos naturais e principalmente da água. A cobrança, com objetivo da racionalização do uso da água, baseia-se no pressuposto de que, quanto mais um indivíduo tiver de pagar por um bem, mais racional será o seu uso.

Além da racionalização do uso de cada indivíduo, há também a racionalização do uso na bacia que se traduz na alocação ótima da água entre os usuários. A otimização da alocação pode se dar em termos hidrológicos, econômicos, políticos ou sociais. Segundo o art. 20 da Lei 9.433, todos os usuários sujeitos à outorga serão cobrados. Portanto, a base de cálculo para a cobrança é a vazão outorgada. Com isso, institui-se no Brasil uma abordagem que integra um instrumento econômico (cobrança pelo uso da água) a um instrumento de regulamentação ou comando-e-controle (outorga). Com a cobrança associada à outorga, a tendência é de que cada usuário venha a solicitar outorga correspondente à sua real necessidade. ${ }^{34}$

O objetivo inicial da cobrança deveria ser a recuperação total dos custos de operação e manutenção do sistema de gerenciamento de recursos hídricos e a recuperação parcial dos custos de investimento dos planos de bacia. Assim, a cobrança não implica em novo tributo, mas a contraprestação a ser paga pela utilização da água, proporcional ao uso, consistindo em receita originária da União ou do Estado.

31 Art. 15, Lei 9.433/97

32 Cf. Desafios do regulador. Rio de Janeiro: Synergia: CEEE/FGV, 2009. p. 96.

33 A gestão dos serviços públicos de energia é de competência da ANEEL, assim dispondo o art. 3², Lei 9.427/96; também a Lei 9.074/95, nos termos dos artigos $4^{\circ}$ a 18, define as algumas etapas e formas de prestação dos serviços públicos de energia elétrica, sendo, dentre estas, a geração de energia a etapa estritamente ligada ao uso dos potenciais hidrelétricos.

34 KELMAN. J. Op. Cit., p. 97. 
Ou seja, é um preço público disciplinado pelo Direito Financeiro, e não receita derivada do patrimônio dos administrados (tributo, p. ex.), mesmo porque esta é a forma disciplinada para racionalizar o uso do bem, paga mais quem dele se utiliza em maior quantidade.

\section{O NOVO MODELO CONSTITUCIONAL}

A constitucionalização do Direito, conforme Barroso ${ }^{35}$, associa-se a um "[...] efeito expansivo das normas constitucionais, cujo conteúdo material e axiológico se irradia, com força normativa, por todo o sistema jurídico". 0 constitucionalista entende que, nessas circunstâncias, a Constituição deixa de ser um sistema em si, com as estruturas que lhe são ínsitas, "[...] mas também um modo de olhar e interpretar os demais ramos do Direito". Naquilo que tange o domínio do direito administrativo, defende que surgiu um novo paradigma, superando ou reformulando o tradicionalismo relacionado à ideia de supremacia do interesse público sobre o interesse privado; substituição da concepção de legalidade pela de juridicidade; e a possibilidade de controle do mérito do ato administrativo.

O modelo atual de direito constitucional, designado por alguns autores como neoconstitucionalismo, identifica o constitucionalismo democrático do pós-guerra, este que é marcado pela força normativa da Constituição, sendo certo que três grandes transformações desordenaram o conhecimento convencional naquilo que se refere à aplicação do direito constitucional ${ }^{36}$ : a Constituição sendo reconhecida como dotada de força normativa; o expansionismo da jurisdição constitucional; e o crescimento de uma nova dogmática da interpretação constitucional.

Este neoconstitucionalismo, entre outras exigências, requer técnicas de ponderação sofisticadas, mormente no que tange aos direitos fundamentais e sua efetivação. Se entender-se que o direito ao ambiente equilibrado é fundamental, a argumentação jurídica- tão cara à ideia das soluções dos problemas inerentes ao Direito contemporâneo -, em defesa do bem em tela se faz necessária, tendo-se em conta que a sociedade atual é de risco e perigo, por conta da ausência da ponderação entre desenvolvimento (urbano e econômico) e meio ambiente equilibrado, o que comprometerá o acesso à agua, a despeito de existirem instrumentos e entidades/órgãos reguladores aptos a fornecer respostas "eficientes". 0 espaço deliberativo proporcionado no Sistema de Gerenciamento Hídrico brasileiro é notório, mas ainda bastante imperceptível pela sociedade, que apenas reconhece o problema quando se está diante de um caos ou quase isso. O papel da Agência Nacional de Águas, nesse contexto neoconstitucionalista, é mais importante do que a mera regulação da vazão, outorga de uso ou controle hidrológico, mas um chamamento institucional no sentido de garantir a transparência do modelo ao qual lhe compete gerir.

\section{CONSIDERAÇÕES FINAIS}

Num momento em que a transposição de rios ou a racionalização do uso da água são temas que se tornam de conhecimento público, verifica-se que a Lei 9.433/97 dispõe de um moderno sistema de regulação sobre o bem hídrico. Qualquer intervenção estatal no sentido de restringir o uso de água tem que estar pautada em critérios técnicos, concomitante a um amplo debate envolvendo todos os agentes (público e privados) dotados de competência legal e de interesse econômico e social na resolução do problema que se pretenda abordar.

35 BARROSO, L.R. Curso de direito constitucional contemporâneo: os conceitos fundamentais e a construção do novo modelo.

5 ed. São Paulo: Saraiva, 2015. p. 530.

36 Ibdem. p. 296 
O sistema regulatório de recursos hídricos possui características que o diferenciam dos demais (e.g., energético e telecomunicações). Ele é efetivamente democrático, transparente e participativo. Os comitês de bacias são um indicativo disso, pois, ainda que a decisão final caiba ao órgão dirigente máximo da Autarquia reguladora, haverá uma percepção dos anseios da sociedade/usuários. Da mesma forma, o pagamento pelo uso da água não é uma tarifa de serviço público. É algo mais legítimo, que se resume a preservar o bem para futuras gerações, independente de qualquer orientação política ou partidária.

Todos esses elementos garantem o consensualismo na Administração Pública, criando um ambiente de confiança na melhor solução dos impasses surgidos em decorrência da potencialidade de carência desse elemento da natureza, a água. 


\section{REFERÊNCIAS}

ANTUNES, P.B. Direito Ambiental. 9 ed. Rio de Janeiro: Lumen Juris. 2006.

AQUINO, L.C.S. et al. A bacia do rio Paraíba do Sul: uma análise do meio físico e da paisagem fluvial. In: ARAÚJO, L.M.; BIZERRIL, C.R.F.; TOSIN, P.C. (Orgs.). Contribuição ao conhecimento da bacia do rio Paraíba do Sul: coletânea de estudos. Rio de Janeiro: ANEEL/CPRM, 1998. p. 1-13.

ARAGÃO, A.S. Agências reguladoras e a evolução do direito administrativo econômico. 2 ed. São Paulo: Forense, 2003.

BARROSO, L.R. Curso de direito constitucional contemporâneo: os conceitos fundamentais e a construção do novo modelo. 5 ed. São Paulo: Saraiva, 2015.

BERCOVICCI, G. Dilemas do estado federal brasileiro. Porto Alegre: Livraria do Advogado, 2004.

BRASIL. Constituição da República Federativa do Brasil de 1988. Disponível em: <http://www.planalto. gov.br/ccivil_03/Constituicao/ConstituicaoCompilado.htm>. Acesso em: vários.

Lei n 9.074 , de 7 de julho de 1995. Estabelece normas para outorga e prorrogações das concessões e permissões de serviços públicos e dá outras providências. Disponível em:

< http://www.planalto.gov.br/ccivil_03/Leis/L9074compilada.htm >. Acesso em: vários.

. Lei n 9.427, de 26 de dezembro de 1996. Institui a Agência Nacional de Energia Elétrica - ANEEL, disciplina o regime das concessões de serviços públicos de energia elétrica e dá outras providências. Disponível em: <http://www.planalto.gov.br/ccivil_03/Leis/L9427cons.htm>. Acesso em: vários.

Lei $n^{\circ}$ 9.433, de 8 de janeiro de 1997. Institui a Política Nacional de Recursos Hídricos, cria o Sistema Nacional de Gerenciamento de Recursos Hídricos, regulamenta o inciso XIX do art. 21 da Constituição Federal, e altera o art. $1^{\circ}$ da Lei $n^{\circ} 8.001$, de 13 de março de 1990, que modificou a Lei $n^{\circ}$ 7.990, de 28 de dezembro de 1989. Disponível em: <http://www.planalto.gov.br/ccivil_03/Leis/L9433. htm>. Acesso: vários.

Lei $n^{\circ}$ 9.984, de 17 de julho de 2000. Dispõe sobre a criação da Agência Nacional de Águas ANA, entidade federal de implementação da Política Nacional de Recursos Hídricos e de coordenação do Sistema Nacional de Gerenciamento de Recursos Hídricos, e dá outras providências. Disponível em: <http://www.planalto.gov.br/ccivil_03/Leis/L9984.htm>. Acesso em: vários.

Lei $n^{\circ} 10.683$, de 28 de maio de 2003. Dispõe sobre a organização da Presidência da República e dos Ministérios, e dá outras providências. Disponível em: < http://www.planalto.gov.br/ccivil_03/ Leis/2003/L10.683compilado.htm >. Acesso em: vários.

Lei Complementar $\mathrm{n}^{\circ}$ 140, de 8 de dezembro de 2011. Fixa normas, nos termos dos incisos III, VI e VII do caput e do parágrafo único do art. 23 da Constituição Federal, para a cooperação entre a União, os Estados, o Distrito Federal e os Municípios nas ações administrativas decorrentes do exercício da competência comum relativas à proteção das paisagens naturais notáveis, à proteção do meio ambiente, ao combate à poluição em qualquer de suas formas e à preservação das florestas, da fauna e da flora; $\mathrm{e}$ altera a Lei no 6.938, de 31 de agosto de 1981. Disponível em: <http://www.planalto.gov.br/CCIVIL_03/ LEIS/LCP/Lcp140.htm>. Acesso em: vários. 
DERANI, C. Direito ambiental econômico. São Paulo: Max Limonad, 1997.

GARRIDO, R.J.S. Estágio atual dos aspectos institucionais da gestão de recursos hídricos no Brasil. 2a ed. Brasília: MMA/SRH, 1999.

GRANZIERA, M.L.M. Direito das águas. $2^{\mathrm{a}}$ ed. São Paulo: Atlas, 2003.

KELMAM, J. Desafios do regulador. Rio de Janeiro: Synergia: CEEE/FGV, 2009.

LEAL, M.S. Gestão ambiental de recursos hídricos: princípios e aplicações. Rio de Janeiro: CPRM, 1998.

MACHADO, P.A.L. Recursos Hídricos - direito brasileiro e internacional. São Paulo: Malheiros. 2002.

Direito ambiental brasileiro. $14^{\mathrm{a}}$ ed. São Paulo: Malheiros, 2006

MARQUES NETO, F.A. Parecer. Projeto de Lei no 5296/2005: diretrizes para os serviços públicos de saneamento básico e Política Nacional de Saneamento Básico (PNS). Disponível em: <http://www. bvsde.paho.org/bvsacd/cd63/diretrizes/Floriano7.pdf>. Acesso em: vários.

SILVA, J.A. Aplicabilidade das normas constitucionais. $4^{\text {a }}$ ed. São Paulo: Malheiros, 2000.

TOMANIK, C.P. Direito das águas no Brasil. São Paulo: Revista dos Tribunais, 2006. 